\title{
Breastfeeding as a Specific Value in Women's Lives: The Experiences and Decisions of Breastfeeding Women
}

\author{
Margareta Lööf-Johansson, Mats Foldevi and Carl-Edvard Rudebeck
}

\section{Linköping University Post Print}

N.B.: When citing this work, cite the original article.

This is a copy of an article published in Breastfeeding Medicine

(C) 2013 Copyright: Mary Ann Liebert, Inc.

Breastfeeding Medicine is available online at: http://online.liebertpub.com.

Original Publication:

Margareta Lööf-Johansson, Mats Foldevi and Carl-Edvard Rudebeck, Breastfeeding as a Specific Value in Womens Lives: The Experiences and Decisions of Breastfeeding Women, 2013, BREASTFEEDING MEDICINE, (8), 1, 38-44.

http://dx.doi.org/10.1089/bfm.2012.0008

Copyright: Mary Ann Liebert, Inc http://www.liebertpub.com/

Postprint available at: Linköping University Electronic Press http://urn.kb.se/resolve?urn=urn:nbn:se:liu:diva-90209 



\title{
Breastfeeding as a Specific Value in Women's Lives: The Experiences and Decisions of Breastfeeding Women
}

\author{
Margaretha Lööf-Johanson,, Mats Foldevi,, and Carl Edvard Rudebeck ${ }^{2}$
}

\begin{abstract}
Background: Worldwide, breastfeeding is recommended for every woman who gives birth to a child. The propensity to breastfeed varies. There is considerable knowledge about the experiences and circumstances that affect the decision to breastfeed, but knowledge about what actually generates the decision's force still needs to be increased. The aim of this study was to gain knowledge of how the decision to breastfeed is initiated and upheld.

Subjects and Methods: Eighteen women from three generations were interviewed, and the data were analyzed by qualitative content analysis.

Results: Six categories were revealed: "Task," "Instinct," "Silent Impact," "Conflicts," "Job," and "Joy." The women took on the Task of breastfeeding during pregnancy. The will to breastfeed was also recognized as an Instinct. The older women remained more in the background, exerting a Silent Impact. Parents' agreement that mothers remain at home and breastfeed for the first 6 months could be considered disturbing from a gender equality perspective. Competition arose between spouses, which could lead to Conflicts at weaning. The mothers in the study chose to stay home to do the Job and experience the Joy of breastfeeding.

Conclusions: A summarizing theme was the specific life value of breastfeeding, encompassing feelings of coherence, pleasure, and pride, regardless of generation affiliation. As the favorable interplay of biological, sensual, relational, and social elements this value upheld the decision to breastfeed. It compensated for the effort and negative experiences, and as a finding, it appears to be transferable among breastfeeding mothers in other developed countries.
\end{abstract}

\section{Introduction}

$\mathbf{W}$ ORLDWIDE, BREASTFEEDING is recommended for every woman who gives birth to a child..$^{1,2}$ On a population level, however, women's propensity to breastfeed changes over time, depending on conditions such as age, occupation, income, and social group affiliation. ${ }^{3-5}$ Parental insurance systems greatly influence a woman's possibility to breastfeed. ${ }^{6-9}$ The tension between a woman's reproductive role and her struggle for gender equality has been shown to influence the decision to breastfeed. ${ }^{10-12}$

Health care may support a mother's decision to continue breastfeeding when problems arise, ${ }^{13-17}$ but trends in societies in the rates of breastfeeding result from decisions made by large numbers of women involved in apparently ordinary breastfeeding. External influences interact with an individual woman's reality in very concrete ways when a mother arrives home to introduce breastfeeding. ${ }^{18,19}$ Problems are very common and often unforeseen. When the baby is unsettled, insufficient nurturing is feared the cause, which paves the way for bottle feeding. The degree of support from the father may be decisive. ${ }^{20}$ In a recent literature review, breastfeeding intention, breastfeeding self-efficacy, and social support were found to be modifiable factors influencing women's breastfeeding decisions. ${ }^{14}$

We know that influences within the family from experienced women such as mothers and grandmothers can be decisive in the decision to breastfeed. ${ }^{21,22}$ Familial experience of breastfeeding has been shown to increase the rate of breastfeeding among women with low incomes.

When the individual experience of breastfeeding is approached through qualitative interviewing, successful breastfeeding has, in a study from the United States, been found to be a complex interactive process with mutual satisfaction of maternal and infant needs: "working in harmony." ${ }^{23}$ In the study of Manhire et al. ${ }^{24}$ from New Zealand, women's commitment and persistence helped them persevere even when facing physical difficulties or unsupportive

\footnotetext{
${ }^{1}$ Department of Medical and Health Sciences, University of Linköping, Linköping, Sweden
}

${ }^{2}$ Department of Community Medicine, University of Tromsö, Tromsö, Norway. 
professional care providers. This added satisfaction to the overall experience. Individual, cultural, and social dimensions can make breastfeeding "greater than its biology." In the study of Schmied and Barclay ${ }^{25}$ from Australia, breastfeeding was central to the informants' experience of motherhood. The study also showed them as strongly committed to breastfeeding. Breastfeeding was an embodied experience that was difficult to articulate: for some, connected, harmonious, and pleasurable, whereas for others, disruptive, unpleasant, and violent, whereby they ceased breastfeeding to re-establish their former body shapes.

In summary, there is substantial knowledge about the experiences and circumstances that affect the decision to breastfeed, but what actually generates the decision's force is less clear. The process is much more complex than just women with positive experiences and conditions tend to breastfeed, whereas those less fortunate do not.

Our aim in this study was therefore, from a Swedish perspective, to gain knowledge of how the decision to breastfeed is initiated and upheld and to compare with findings from other national contexts. We also specifically sought to gain a picture of how possible influences from older generations of women were experienced and, within a three-generation perspective, to distinguish experiences of breastfeeding important to the decision and that appear to abide for long periods of time.

\section{Subjects and Methods}

We chose an interview study using a qualitative content analysis method. ${ }^{26,27}$ Qualitative analysis is primarily a method for condensing texts of explorative material and can be applied in various theoretical perspectives on both manifest and latent interpretive levels.

We expected statements of greatly varying content with everything from descriptions of practical problems to personal experiences and hoped from baseline to assure the possibility of analyzing the material on manifest, detailed, and latent levels and therefore judged qualitative content analysis to be well suited to our purpose.

\section{Sample of interviewees}

The study was carried out with three generations of women. The plan was to interview a woman who breastfed, as well as her mother and grandmother, concerning her experiences of breastfeeding and, if possible, the role of the older women. The women were recruited initially via childcare centers and were to have undergone breastfeeding while being in close contact with their mothers or grandmothers. We assumed that the older generations had had experiences of breastfeeding, which was found to be the case. Only women of Swedish origin were interviewed. The childcare center personnel were informed of the project. An information folder was distributed to the new mothers.

Those women showing interest in the study left their telephone numbers. New triads were added to achieve a balance between rural and urban areas (urban was defined as having $>20,000$ inhabitants) and differences in levels of education. Interviews continued until we considered we had a sufficiently large and varied study group to gain relevant accounts of ordinary breastfeeding experiences from different backgrounds and generations. No one who had decided to enroll withdrew from the study. The study group included 18 women, all of whom were new mothers breastfeeding in a stable phase a few months after delivery and living in permanent relationships. Table 1 presents the participating women's ages and career training at the time of the interview.

The study complied with the Declaration of Helsinki and with agreements on Good Clinical Practice. At the time of the interview planning in 2003 and implementation in 2004, there was no requirement for formal ethical approval for qualitative studies of this nature in Sweden. A new regulatory system was introduced in 2005. Recruitment was achieved through individual participants' active decisions. Consent was obtained from all study participants.

\section{Execution of the interviews}

The interviews were carried out by the project leader (M.L.-J.) in the homes of the participants and lasted about 1 hour. All statements were confidential and inaccessible to the other participants. All participants were interviewed concerning their attitudes, feelings, preparations, decisions, and implementation of breastfeeding.

The interviews were opened by the question, "Why have you chosen to breastfeed?" Prepared follow-up questions, the same for all, were posed depending on responses until the field of study was fully covered. The interviews were taped and transcribed verbatim by a secretary.

\section{The analysis}

We began the analysis with repeated readings to gain an overview of the contents. Reading was chiefly aimed toward

Table 1. Participating Women's Ages and Career Training AT THE Time of the INTERviews

\begin{tabular}{lcll}
\hline $\begin{array}{l}\text { Generation, } \\
\text { subject number }\end{array}$ & $\begin{array}{c}\text { Age } \\
\text { (years) }\end{array}$ & \multicolumn{1}{c}{ Profession } & Residence \\
\hline $\begin{array}{l}\text { Breastfeeding, } 1^{\text {st }} \\
\text { 1A }\end{array}$ & 21 & Student & Rural \\
4A & 29 & Lawyer & Urban \\
7A & 28 & Receptionist & Urban \\
10A & 28 & Doctor & Urban \\
13A & 31 & Housewife & Rural \\
16A & 39 & Biologist & Rural \\
18A & 33 & Teacher & Rural \\
Mother of breastfeeding woman, 2nd generation & \\
2B & 39 & Teacher & Rural \\
5B & 54 & Teacher & Rural \\
8B & 54 & Air hostess & Urban \\
11B & 58 & Teacher & Rural \\
14B & 58 & Sick senior & Urban \\
17B & 69 & Decorator & Urban \\
Grandmother, $3^{\text {rd }}$ & generation & & \\
3C & 60 & Caregiver & Rural \\
6C & 82 & Ombudsman & Rural \\
9C & 84 & Hairdresser & Urban \\
12C & 92 & Social worker & Urban \\
15C & 81 & Cleaner & Urban \\
\hline
\end{tabular}

Five breastfeeding women belonged to complete triads. Throughout the text text, a breastfeeding woman is referred to by her number plus the suffix A, her mother by the number plus the suffix B, and her grandmother by the number plus the suffix $\mathrm{C}$. 
the manifest content, that is, the immediate implications of the statements. Later in the analysis the latent content of the statements also became important. ${ }^{27}$ Meaning-bearing units were identified and coded.

Codes were compared and grouped in preliminary subcategories and categories. A synopsis was created, that is, a condensed version of each interview, but still each distinctly associated with the respective informant. This step is a modification of the procedure described by Graneheim and Lundman. ${ }^{27}$ With this measure we sought to assure ourselves that the first process of condensation was rooted in the accounts that made up each interview. The synopses then formed the basis for coding and categorization on the second level, on which the theme of latent content was constructed.

In the analysis process, great emphasis was placed on separating the breastfeeding experience from the experience of giving birth. All expressions difficult to interpret in this respect or connected to the experiencing of the child him- or herself were excluded from the analysis to avoid confusing results. In the initial phase of the analysis, two authors were involved in the first level of coding, conferring to reach agreement. The first author then independently carried out the first level of coding, after which codes and categories were challenged and agreed upon in joint discussions.

\section{Results}

All breastfeeding women and their older relatives contributed to the final result. There was variation in terms of parity and age at breastfeeding. No general differences between the generations were seen, but where generationspecific experiences stood out, they were commented upon. The analysis resulted in six categories: "The Task," "The Instinct," "A Silent Impact," "The Job of Breastfeeding," "The Joy of Breastfeeding," and "Conflicts." The life value of breastfeeding was a theme throughout the categories.

\section{"The Task"}

The decision to breastfeed was intuitive in women before childbirth. They had the faith and conviction that it was natural. The approaching birth, however, often interfered with thought processes and preparations: "My approach was to try" (1A).

The Task could include feelings of duty such as "you should if you can." The older women sometimes underpinned this task by conveying demands and a sense of duty. In several cases the man and woman negotiated an agreement where the woman was to remain at home to perform the task of breastfeeding. The decision to breastfeed at home was experienced by some as uncomfortable from a gender equality viewpoint.

\section{"The Instinct"}

The will to breastfeed was supported by biological instinct. Milk production during pregnancy's later phase enforced the decision to take on the task of breastfeeding. A woman having her first baby could not foresee how the body had its own "breastfeeding agenda" and that it was, moreover, pleasurable to breastfeed: "I became amazed that the body had its own language. My breasts began to tense when the child cried" (10A).
The newborn child's ability to, on his or her own, search for the breast and begin sucking enforced the feeling of instinct. The child took the initiative to breastfeed with his or her search for nourishment: "There were no thoughts but only instinctive behavior" (2B). In the same way the urge to seek the breast could suddenly cease when the child grew older. The instinct to breastfeed remained latent in the woman's body in later life and could be activated by an infant's crying so that a grandmother's breast began to tense.

In situations where the healthcare personnel occasionally left more or less contradictory advice, the mother often trusted the child's needs and her feeling of what was right, that is, she relied on her unique role as mother.

\section{"Silent Impact"}

The older women imparted an attitude to breastfeeding, which could be more or less conscious and apparent to both parties. This "Silent Impact" could be loving and positive, but as mentioned could sometimes enforce a sense of duty. Within this influence was a guiding element built on observation, providing help and support if and when needed. The grandmothers did not intrude but only answered questions when called upon. The elderly women could feel pride, admiration, and joy before their young relatives, who were getting on with breastfeeding even when it did not fit in with how the older women had done it themselves: "I haven't spoken with my daughter about breastfeeding but admire her ability to breastfeed" (3B).

The young women chose to whom they wanted to speak about breastfeeding. For some, their mothers were too emotionally involved, whereas the older grandmothers were easier to talk to. The oldest generation had not, as a rule, spoken to their mothers about breastfeeding but assumed they should breastfeed.

\section{"The Job of Breastfeeding"}

The previously heavy pregnant body now performed the work of breastfeeding that was physically demanding and practically significant. Breasts swelled with milk, became tender, and leaked occasionally. Milk ran down clothing, and women could never quite know when it would come or if it were visible to others. The child's crying could start the ejection reflex when least expected. It created a feeling of being unfresh and unfree, a feeling in strong contrast to those images and conceptions today's society creates of how a woman should look and feel. Despite physical strain, the will to breastfeed did not change. In the study group, the child's or mother's illness was an obstacle to successful breastfeeding. Sores, leaking breasts, and other practical problems were, on the other hand, possible to overcome. Breastfeeding was tiring and demanded round-the-clock presence: "To breastfeed is to live in symbiosis with the child around the clock and one is never free...I have been there every minute...in the ten months since he was born" (7A).

\section{"The Joy of Breastfeeding"}

The competent body that let the milk flow created a feeling of meaningfulness and presence in life, while providing a feeling of connection and meaning described as "the greatest happiness in life." Tiredness was felt to be of another quality 
than usual tiredness, providing pleasant rest and a kind of sleepiness. The symbiosis with the child's lips around the nipple was pleasurable. The feeling of breastfeeding was not presented in romantic language but in more realistic terms. A breastfeeding body was something to be proud of despite hanging breasts. Women expressed their experiences of breastfeeding in terms of reciprocity, intuition, obviousness, self-esteem, unreflecting, nothing unusual, grounded knowledge, and smart. The same means of expression were repeated in all generations. One woman said, "I felt present in life when breastfeeding" (11B), and another said, "One is important" (2B). One grandmother expressed her memories of breastfeeding somewhat more strongly: "If I were to create an historic dream then I am a wet nurse. I am not a queen or a princess. I am a wet nurse, that's all" (5B).

\section{"Conflicts"}

The breasts that had now created milk belonged to the child. They had formerly been a part of a sexual union and could therefore give rise to a conflict of roles for both the father and the mother. The child's needs came first and were considered limited in time.

Breastfeeding ended depending on either the cessation of the child's urge to breastfeed or the mother no longer wanting to breastfeed when she felt it was time to stop. If wills were not in harmony, one party could suffer. A power struggle when shutting down was described when the symbiosis was broken: "The loss for the woman can be greater than for the child" (2B).

An involuntary stop for breastfeeding could occur when it was time for the man's parental leave of absence. Women felt unfinished with the job of breastfeeding and didn't want to lose their breastfeeding roles, which provided pleasure, closeness, and joy, but they had to stop, nonetheless.

The mother could also feel forced to return to working life and even feel competition with her partner taking over the care of the child. At the same time, there could be a longing toward her professional role and wage earning and the obvious gains of completing the gender equality alliance: "Breastfeeding is threatened by gender equality and working life" (16A). One woman saw breastfeeding as a career (13A). The same woman became ill after her last child and could no longer breastfeed and expressed the feeling "as if fired from a 30-year job" (13A).

\section{The life value of breastfeeding}

Breastfeeding appeared throughout the categories as a specific and distinct value in the lives of the women: "The emotional dimension of breastfeeding creates a feeling of having arrived in life" (1C). The life value of breastfeeding referred to powerful and positive experiences of breastfeeding and the meaningfulness it provided. It was firmly tied to breastfeeding and not the encompassing experience of having a child and becoming a mother. The decision and instinct along with the work involved in breastfeeding gave a strong feeling of presence in life. The joy and pleasure it brought provided strong self-esteem to the woman. The life value of breastfeeding included the woman's ability to deal with all practical breastfeeding problems, tiredness, conflicts, and disappointment in, for example, not being able to be at the workplace and enjoy a normal life. The life value of breast- feeding strengthened female identity and instilled a sense of importance regardless of generation affiliation and upheld the decision to breastfeed. The three generations were consonant in describing the life value of breastfeeding despite diverging social conditions for parental leave of absence, gender equality, and accessibility to breastmilk substitutes.

\section{Discussion}

The task and the instinct established the drive to initiate breastfeeding while the decision to continue was upheld by the life value of breastfeeding. This positive force, which we regard as being the favorable interplay of biological, sensual, relational, and social elements formulated in our result categories, affected the breastfeeding women's everyday lives, and as an experience it appeared to continue to strengthen the female identity throughout life. Here, we will set out from the categories and the life value of breastfeeding to discuss our findings in relation to research and theory relevant to our study.

\section{"Task" and "Instinct": cross-pressures}

Expressing the "breastfeeding intention,"14 the women in the study took a stand for breastfeeding during pregnancy without actually having become acquainted with its implications. Displaying even the self-efficacy of breastfeeding, ${ }^{14}$ they believed it would work, and persisted, as did the women in the study of Manhire et al. ${ }^{24}$ In opposition to this spontaneous decision are apparent forces that tend to make breastfeeding a controversial issue in modern society: "Breastfeeding simply did not fit into this first modernistic neurotically insecure culture of the 50's," wrote the Swedish sociologist Hedvig Ekerwald, in Every Mother Is a Daughter. ${ }^{28}$ Today's women live an extroverted life compared with their mothers and grandmothers, and the pace of society is high, and stress is common. In the social debate, breastfeeding is questioned by a more or less negative attitude. Milk substitutes are often chosen instead of breastfeeding. Hausman ${ }^{29}$ discussed how through the marketing of infant formula, the woman's right to breastfeed is camouflaged by an emotional and commercialized rhetoric of choice. Here a well-informed choice, taking into account what is best for the child and the mother, is never the goal. Socioeconomically less privileged mothers are driven to "choose" formula because their social and family conditions often are not supportive of breastfeeding.

Allison Bartlett ${ }^{30}$ saw breastfeeding as an unpredictable and incarnate activity where the breasts possess an inbuilt competence with their own memory and logic. Breastfeeding is hence an essential aspect of female embodiment but, as shown in the study of Schmied and Barclay, ${ }^{25}$ far from always being positively experienced. We call this "Instinct" in our study. One of the women expressed how the body has its own language and the child its own path-finding ability in breastfeeding. Bartlett implied that this ability surpasses biomedical reasoning and feminist positioning. ${ }^{30}$

\section{"Silent Impact": generational influence}

The older women appeared to be intuitively responsive, perhaps something passed down by many generations, possessing a deep feeling for how information should be 
proffered. Here we sense that the older women did not just demonstrate the ways and means of breastfeeding, but that they conveyed the life value of breastfeeding by embodying it. In other studies concerning the maternal grandmother's role the same attitude, "Grandmother's breastfeeding advocacy," from the older women toward the younger breastfeeding women can be seen. ${ }^{13,21,22,31}$

In contrast to these studies the women in our study did not express an unconditional desire for their mother's support and advice. They themselves decided if and from whom they wanted advice. A generational leap may sometimes be necessary.

\section{The "Joy" and the "Job" as the basis for the life value of breastfeeding}

The emotional and positive value of breastfeeding in its very bodily sense seems to be the basis for the life value of breastfeeding. This value is linked to the experience of having a meaningful mission, even if difficult at times. In the same way a pregnancy implies strain, it also provides joy. Our findings clearly confirm the conclusion of Manhire et al. ${ }^{24}$ that "breastfeeding is more than its biology."

Thomson and Dykes ${ }^{32}$ associated the sense of coherence ${ }^{33}$ with breastfeeding and mean that just the sense of coherence is found in the act of breastfeeding. Therefore they have created a model for how these values can be integrated in breastfeeding information.

In the study of Schmied and Barclay ${ }^{25}$ only $35 \%$ experienced breastfeeding as harmonious and sensual. Difficulties and worries appeared in our study as well but were overcome through work and accepted as part of the breastfeeding life's value. In this aspect their experience is quite in accord with the category "Satisfaction" in the study of Manhire et al. ${ }^{24}$ and with the concept of Leff et al. ${ }^{23}$ of "Work in Harmony." The life value, as it appears in our findings, however, goes even further in contributing to personal identity as a whole. We do not believe this to be a real difference, but rather the result of differing research approaches.

In her article "Maternal sexuality and breastfeeding," Alison Bartlett ${ }^{34}$ brought up the aspect of pleasure in breastfeeding, implying it to be part of female sexuality and should therefore not be belittled or associated with guilt. In our interviews there were no explicit accounts of sexual pleasure, which is not to say that it might not add positively to the breastfeeding experience.

\section{Conflicts: breastfeeding in a society striving toward gender equality}

Several of the new parents in the study had agreed that the woman should be home and breastfeed for the first 6 months. According to gender equality research ${ }^{35}$ we know that gender equality between men and women in Sweden functions well as long as there are no children. A new step in the equality process is taken when the first child arrives. Who will stay at home, for how long, and on what economic terms?

The women's educational backgrounds were broad and encompassed all social groups. If the men and women had similar educational backgrounds and incomes, it appeared that the agreement worked well among those interviewed.

When, as in Sweden, society supports extensive parental leave, there is a risk that the parents with the lowest in- comes-as a rule women-subordinate themselves to the family's financial situation and stay home in contradiction to the agreement of the remaining parental leave. ${ }^{36}$ Giving up breastfeeding for the sake of professional work prematurely was, however, not an alternative for our participants. Most of the older women, like many working women today throughout the world, were not encompassed by the extensive parental insurance coverage of today's parents, causing some to break off breastfeeding, which was very painful.

Breastfeeding of itself is not an argument against gender equality but, on the contrary, a question of how parents act in a gender equality perspective. The decision and standpoint as to how breastfeeding should be carried out can be a new strategic and decisive moment for the continuing equality process between parents.

\section{Success or failure: the life value of breastfeeding becoming normative}

Healthcare personnel are well trained and dedicated to achieving the goal formulated by the World Health Organization to breastfeed for 6 months. In eagerness to support breastfeeding individual circumstances for the woman may become secondary. Too much "supportive pressure" can create stress. The life value of breastfeeding cannot be proclaimed, but mothers may be supported to find it on their own.

Burns et al. ${ }^{37}$ pointed out the language used when speaking to women about their breastfeeding in their review of 17 qualitative studies. Breastfeeding experiences are often described in terms of "success or failure." A good mother breastfeeds, and failure in breastfeeding is the same as being a "bad mother."

Using this sort of language can cause the tone of dialogue, advice, and debate to easily become moralizing and provide an image of breastfeeding as difficult and frightening. The contingent implication of breastfeeding may have certain salience in the brittle situation of mothers of preterm infants. ${ }^{38}$ With too much professional focus on milk production, the relational interplay may be overlooked, and breastfeeding becomes a labor without the reciprocity of "work in harmony," ${ }^{23}$ thus damaging the mother-infant relation. We have to conclude that breastfeeding in itself is not a life value, but that it has great potential in this regard to be realized in the interplay with other conditions.

The women in our study had a personal experience of breastfeeding as a life value having another nuance than success. Despite this, an unwanted discontinuation of breastfeeding was felt as a "failure."

\section{Limitations}

The study sample was composed of women who breastfed and whose mothers and mother's mothers, in a so-called triad, were primarily considered to be available for interviews. With this special target group we did not see it as realistic to strive for strategic sampling other than in terms of education and area of living. The study group, however, turned out to be varied in terms of parity and age at breastfeeding; thus, we think that our findings are based in a reasonably varied and ordinary Swedish maternal reality. Detailed accounts of breastfeeding duration were not an issue because we were primarily interested in the initiation and upholding of the 
decision. Women with another ethnic background and breastfeeding tradition were excluded. Breastfeeding, at least from the start, was an inclusion criterion. To primarily study breastfeeding-negative viewpoints was outside the aim of the study.

The fact that $80 \%$ of children born in Sweden in 2007 were breastfed completely or partially after 4 months speaks for the positive attitude toward breastfeeding expressed in our study. Interviews were carried out during 2004, but our findings are corroborated by more recent studies, as well as by the theories of female body image, referred above.

\section{Conclusions}

Regardless of generation affiliation, the task and the instinct established the drive to initiate breastfeeding while the decision to continue was upheld by the life value of breastfeeding: the favorable interplay of biological, sensual, relational, and social elements. The older women constituted a discrete but strong force of influence, and the young breastfeeding women chose from whom to accept support. The life value of breastfeeding was contested by strain and pain as well as by role and gender conflicts but still formed the drive to breastfeed and contributed to women's identities. This finding appears to be transferable among women in developed countries. Further studies will determine if it is more generally transferable.

\section{Acknowledgments}

This work is supported by grants from the Research Council of Southern Sweden. The funding sources had no role in study design, data collection and analysis, or interpretation and presentation of the results.

\section{Disclosure Statement}

No competing financial interests exist.

\section{References}

1. World Health Organization. Global Strategy for Infant and Young Child Feeding. World Health Organization, Geneva, 2003.

2. Hoddinott $\mathrm{P}, \mathrm{Craig}$ LC, Britten J, et al. A serial qualitative interview study of infant feeding experiences: Idealism meets realism. BMJ Open 2012;2(2):e000504.

3. Thulier D. Breastfeeding in America: A history of influencing factors. J Hum Lact 2009;25:85-94.

4. Kronborg H, Vaeth M. The influence of psychosocial factors on the duration of breastfeeding. Scand J Public Health 2004;32:210-216.

5. Andrew N, Harvey K. Infant feeding choices: Experience, self-identity and lifestyle. Matern Child Nutr 2011;7:48-60.

6. Payne D, James L. Make or break. Mother's experiences of returning to paid employment and breastfeeding: A New Zealand study. Breastfeed Rev 2008;16:21-27.

7. Choudhry K, Wallace LM. Breast is not always best: South Asian women's experiences of infant feeding in the UK within an acculturation framework. Matern Child Nutr 2012;8:72-87.

8. Ministry of Employment. Parental Leave Act, SFS 1995:584. May 12, 2008. www.sweden.gov.se/sb/d/5807/a/104985 (accessed September 2012).
9. Protection, Promotion and Support of Breastfeeding in Europe: Review of Interventions. Istituto di Ricovero e Cura a Carattere Scientifico (IRCCS) "Burlo Garofolo," Trieste, Italy, 2004.

10. Van Esterik P. Breastfeeding and feminism. Int J Gynaecol Obstet 1994;47(Suppl):S41-50; discussion S50-S54.

11. Freedman J. Feminism-An Introduction. Open University Press, New York, 2001.

12. Johnson S, Williamson I, Lyttle S, et al. Expressing yourself: A feminist analysis of talk around expressing breast milk. Soc Sci Med 2009;69:900-907.

13. Dykes F, Moran VH, Burt S, et al. Adolescent mothers and breastfeeding: Experiences and support needs-An exploratory study. J Hum Lact 2003;19:391-401.

14. Meedya S, Fahy K, Kable A. Factors that positively influence breastfeeding duration to 6 months: A literature review. Women Birth 2010;23:135-145.

15. Dennis CL. Breastfeeding initiation and duration: 1990-2000. A literature review. J Obstet Gynecol Neonatal Nurs 2002;31:12-32.

16. Li R, Fein SB, Chen J, et al. Why mothers stop breastfeeding: Mother's self-reported reasons for stopping during the first year. Pediatrics 2008;122(Suppl 2):S69-S76.

17. Schmied V, Beake S, Sheehan A, et al. Women's perceptions and experiences of breastfeeding support: A metasynthesis. Birth 2011;38:49-60.

18. Hjälmhult E, Lomborg K. Managing the first period at home with a newborn: A grounded theory study of mother's experiences. Scand J Caring Sci 2012 February 6 [Epub ahead of print]. doi: 10.1111/j.1471-6712.2012.00974.x.

19. Bellintxon M, Zaragüeta MC, Adrián MC, et al. Initiating breastfeeding: Experiences of first-time mothers [in Spanish]. An Sist Sanit Navar 2011;34:409-418.

20. Colin WB, Scott JA. Breastfeeding: Reasons for starting, reasons for stopping and problems along the way. Breastfeed Rev 2002;10:13-19.

21. Grassley J, Eschiti V. Grandmother breastfeeding support: What do mothers need and want? Birth 2008;35:329-335.

22. Reid J, Schmied V, Beale B. I only give advice if I am asked: Examining the grandmother's potential to influence infant feeding decisions and parenting practices of new mothers. Women Birth 2010;23:74-80.

23. Leff EW, Gagne MP, Jefferis SC. Maternal perceptions of successful breastfeeding. J Hum Lact 1994;10:99-104.

24. Manhire KM, Hagan AE, Floyd SA. A descriptive account of New Zealand mother's responses to open-ended questions on their breastfeeding experiences. Midwifery 2007;23:372-381.

25. Schmied V, Barclay L. Connection and pleasure, disruption and distress: Women's experience of breastfeeding. J Hum Lact 1999;15:325-334.

26. Elo-Satu, Kyngäs H. The qualitative content analysis process. J Adv Nurs 2008;62:107-115.

27. Graneheim UH, Lundman B. Qualitative content analysis in nursing research: Concepts, procedures and measures to achieve trustworthiness. Nurse Educ Today 2004;24: 105-112.

28. Ekerwald H. Every Mother Is a Daughter [in Swedish]. Symposium Stockholm/Stehag, 2002.

29. Hausman BL. Women's liberation and the rhetoric of "choice" in infant feeding debates. Int Breastfeed J 2008;3:10.

30. Bartlett A. Breastfeeding as headwork: Corporeal feminism and meanings for breastfeeding. Womens Studies Int Forum 2002;25:373-382.

31. Ekström A, Widström AM, Nissen E. Breastfeeding support from partners and grandmothers: Perceptions of Swedish women. Scand J Public Health 2005;33:424-431. 
32. Thomson G, Dykes F. Women's sense of coherence related to their infant feeding experiences. Matern Child Nutr 2011;7:160-174.

33. Antonovsky A. Unraveling the Mystery of Health: How People Manage Stress and Stay Well. Jossey-Bass Social and Behavioral Science Series/Jossey-Bass Health Series. Jossey-Bass, San Francisco, 1987.

34. Bartlett A. Maternal sexuality and breastfeeding. Sex Educ 2005;5:67-77.

35. SOU:1997:138-139. Swedish Investigation of Women Power, Stockholm, Sweden.

36. Dahl L. Göteborgs Studies in Educational Sciences, Vol. 220: The Condition of the Breastfeeding Practice [in Swedish]. Göteborgs Universitet, Goteborg, Sweden, 2004.

37. Burns E, Schmied V, Sheehan A, et al. A metaethnographic synthesis of women's experience of breastfeeding. Matern Child Nutr 2010;6:201-219.
38. Flacking R, Ewald U, Starrin B. "I wanted to do a good job": Experience of 'becoming a mother' and breastfeeding in mothers of very preterm infants after discharge from a neonatal unit. Soc Sci Med 2007;64:2405-2416.

Address correspondence to: Margaretha Löof-Johanson, MD Department of Medical and Health Sciences University of Linköping Köpmangatan 9 Mörbylånga, 38650, Sweden

E-mail: 0485.40311@telia.com 